\title{
Migraine Headache as a Presenting Feature of Multiple Sclerosis: A Case Report
}

\author{
Mohammad Mahdi Rabiei $^{\circledR}$, Zahra Cheraghi $^{1}$, Mahtab Ramezani $^{*}{ }^{*}$, Hossein Pakdaman $^{3}$ \\ ${ }^{1}$ Faculty of Medicine, Shahid Beheshti University of Medical Sciences, Tehran, Iran \\ ${ }^{2}$ Skull Base Research Center, Loghman Hakim Hospital, Shahid Beheshti University of Medical Sciences, Tehran, Iran \\ ${ }^{3}$ Brain Mapping Research Center, Loghman Hakim Hospital, Shahid Beheshti University of Medical Sciences, Tehran, Iran
}

\begin{abstract}
Multiple sclerosis (MS) is a chronic inflammatory disease, causing neuronal demyelination and axonal damage in the central nervous system. Symptoms of MS vary widely because of different grades of sensory, motor, and cognitive dysfunctions. Although headache as the initial symptom of MS is rare, it is a common comorbidity that affects most patients. However, it is unclear that the headache manifestation in newly diagnosed people with MS should be considered as an MS attack or merely a comorbid condition. We report the case of a 31-year-old woman with newly diagnosed MS who presented with exacerbation of headache episodes without any abnormal neurological exam findings. The headaches did not respond to nonsteroidal anti-inflammatory drugs and triptans. After administration of methylprednisolone, the headaches were significantly improved, and during 3 months of follow-up receiving glatiramer acetate, no episode of headache has occurred. This case demonstrates the possible relationship between migraine and MS in newly diagnosed patients. New-onset headaches, a change in the pattern of previous episodes, and inadequate clinical drug response to headache treatment should all be taken seriously and warrant further investigation. Thereby, early diagnosis and proper treatment for patients with MS could improve their quality of life.

Keywosrds: Migraine disorders, Headache, Multiple sclerosis, Treatment outcome
\end{abstract}

*Correspondence to

Mahtab Ramezani, MD

Assistant professor of

Neurology, Skull Base Research

Center, Loghman Hakim

Hospital, Shahid Beheshti

University of Medical Sciences

South Kargar Ave., Kamali St.,

Tehran, Iran.

Postal code: $+98-1333635445$

; Tel: +98-2151025582; Fax:

$+98-2155416130$

Email: drramezani23@gmail.

com

Published online 30 October 2021

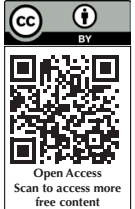

Citation: Rabiei MM, Cheraghi Z, Ramezani M, Pakdaman H. Migraine headache as a presenting feature of multiple sclerosis: a case report. Clin Neurosci J. 2021;8(4):208-211. doi:10.34172/icnj.2021.41.

\section{Introduction}

Multiple sclerosis (MS) is a chronic inflammatory disease, causing neuronal demyelination and axonal damage in the central nervous system (CNS). ${ }^{1}$ The average age of MS onset is between 20 and 40 years, and women are three times more affected than men. ${ }^{1-3}$ Considering the sensory, motor, and cognitive dysfunctions, MS has various clinical presentations. ${ }^{1,4}$ Although headache as the initial symptom of MS is rare, it is a common comorbidity that affects $57 \%$ of the patients. ${ }^{1,2}$ Migraine and tensiontype headaches are the most prevalent headaches reported in patients with MS, respectively. ${ }^{2,5}$ Migraine is typically a unilateral and pulsating headache lasting 4 to 72 hours and negatively affects quality of life. ${ }^{6}$ There are demographic similarities between MS and migraine, including young age at onset and being more frequent in women than men. ${ }^{7}$ On the other hand, the co-occurrence of headaches and MS could be explained by the similarity of inflammatory processes in both diseases, leading to meningeal inflammation and cortical demyelination. ${ }^{2,8}$ Moreover, the location of demyelinating brain lesions and some medications are suggested as the etiology of headaches. ${ }^{8-10}$

Despite the high prevalence of migraine and migrainelike headaches among patients with MS, the occurrence of these conditions as the only manifestation of MS is quite unusual. A few studies reported migraine-like headaches as the first presentation of MS attack. ${ }^{11-13}$ Status migrainosus as a presenting symptom of MS is much rarer. ${ }^{14}$ Herein, we report a case with status migrainosus as an MS attack with new T2 lesions and provide a comprehensive review of MS attacks presenting migraine headaches.

\section{Case Presentation}

\section{Case Summary}

A 31-year-old woman was referred for evaluation after three days of left-sided slowly progressive blurred vision, with periocular pain aggravated by eye movements. She had a history of migraine without aura once every two months since adolescence. Her neurological examination was notable for a relative left afferent pupillary defect and left side visual acuity of 30/70; however, the fundoscopic examination was normal. Brain magnetic resonance

(C) 2021 The Author(s). This is an open access article distributed under the terms of the Creative Commons Attribution License (http:// creativecommons.org/licenses/by/4.0/), which permits unrestricted use, distribution, and reproduction in any medium, provided the original work is properly cited. 
imaging (MRI) revealed five ovoid T2 hyperintense lesions greater than $3 \mathrm{~mm}$ in diameter. One lesion was juxtacortical, while the remaining lesions were in the periventricular region with a Dawson finger pattern. None of the lesions demonstrated contrast enhancement, and MRI of the cervical and thoracic spinal cord was normal. Other investigations including metabolic panel, inflammatory markers, and cerebrospinal fluid (CSF) analysis were unrevealing.

Intravenous (IV) methylprednisolone $1 \mathrm{~g} / \mathrm{d}$ was given for five days, and she showed a good recovery after 10 days. The clinically isolated syndrome diagnosis was established, and the patient was considered for follow-up. After 4 months, she experienced moderate to severe right temporoparietal throbbing headaches associated with blurred vision, sensitivity to light, sound, and nausea. Her headache was more severe than previous ones, and she found neither nonsteroidal anti-inflammatory drugs nor triptans to be effective anymore. She had started prednisone $50 \mathrm{mg}$ for 10 days along with an antiemetic drug due to probable diagnosis of status migrainosus, and preventive therapy consisted of amitriptyline and propranolol was administered. A Brain MRI with and without gadolinium was requested (Figure 1A, B, C, D). Since the headache was not responsive to symptomatic therapy, IV methylprednisolone was given for 3 days which improved her headache by approximately $70 \%$. According to new T2-weighted lesions and clinical symptoms of headache, clinically definite MS was established, and glatiramer acetate was administered. On the three months follow-up, she mentioned complete recovery of migraine headaches.

\section{Discussion}

Patients with MS experience headaches remarkably higher than the normal population. Migraine, migrainelike, and tension-type headaches are the most reported subtypes. ${ }^{8}$ Previous research has indicated an association between different MS subtypes and a higher prevalence of particular headache. Migraines are more common in relapsing-remitting MS than in other MS variants. ${ }^{10}$
However, it is unclear whether headache is a symptom of an MS attack or merely a comorbid condition in newly diagnosed people with MS. ${ }^{8}$ We report a case that showed the association between the onset of status migrainosus with progressive T2-fluid-attenuated inversion recovery (FLAIR) and new gadolinium-enhancing demyelinating lesions on the initial and subsequent MRIs.

Several possible mechanisms have been suggested for the correlation of migraine and MS.,8,10 Migraine may occur in patients with MS during an episode of sterile meningeal inflammation, primarily detected by activating nociceptors in the intracranial meninges. ${ }^{15}$ The inflammatory process triggered by B lymphocytes during MS attacks affected the meninges. ${ }^{16-18}$ Moreover, antibody formation following a localized humoral immune response could result in meningeal inflammation and cortical demyelination, leading to headaches. ${ }^{17-19}$ Klein and colleagues reported stabbing headaches during an MS patient's relapse without any new T2-weighted lesions. ${ }^{20}$ However, during headaches, CSF analysis showed inflammatory pleocytosis that originated from meningeal inflammation. ${ }^{20}$ Mariotti et al reported a pediatric patient with MS who suffered from a migrainelike headache at the onset of the disease. Also, the first relapse was only presented with status migrainosus. Brain MRI revealed leptomeningeal engorgement and effacement of subarachnoid spaces as a result of meningeal inflammation at the onset and during the relapse of the disease. ${ }^{11}$ Another suggested mechanism for migraine-like headaches in patients with MS could be explained by an increase in intracranial pressure following a demyelinating lesion resulting in cerebral edema; as Marriott and colleagues mentioned, lumbar puncture significantly improved these types of headaches. ${ }^{11,12}$

Additionally, disease-modifying therapies (DMTs) could cause headaches in patients with MS. ${ }^{7,10,21}$ Interferonbeta (INF- $\beta$ ) is a subgroup of DMTs that may exacerbate pre-existing migraines or develop a new migraine episode in patients with MS without any history of headache. Prior research demonstrated that the incidence of headaches in patients who received DMTs other than
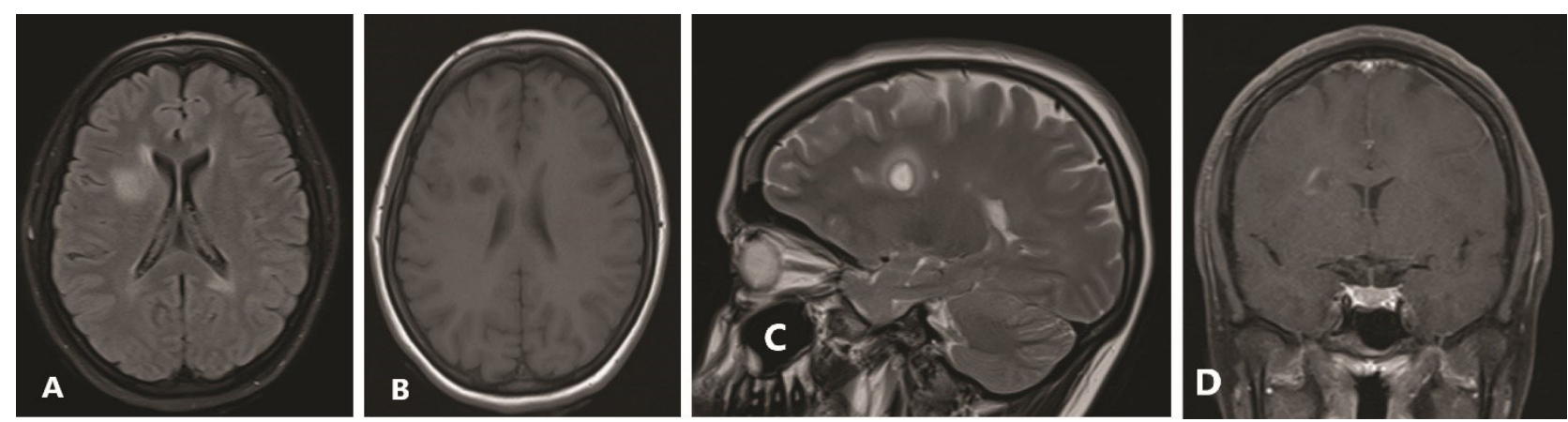

Figure 1. Axial fluid-attenuated inversion recovery (FLAIR) and T1- and T2-weighted images demonstrate a new periventricular lesion (A, B, C). Feature supporting acute blood-brain barrier compromise (gadolinium enhancement) was observed on the post-contrast axial T1weighted image with open ring enhancement (D). 
INF did not differ significantly compared with placebo. ${ }^{7,10}$ However, Mariotti and colleagues showed that patients with MS did not experience new status migrainosus and migraine-like headaches by receiving IFN. ${ }^{11}$ On the other hand, Alroughani and colleagues reported a clinically definite patient with MS with status migrainosus as the first presentation that fingolimod administration resulted in headache improvement during the follow-up period. ${ }^{14}$ These findings could highlight the possibility of migraine headache as the only manifestation of MS attack in the patients.

It was observed that the demyelinating lesions located in periaqueductal gray matter (PAG) and midbrain are related to migraine presentation during an MS attack. ${ }^{2,12,22}$ PAG is a pain modulating station that provides the antinociceptive effect on afferent pain signals from the spinal cord. ${ }^{23}$ Demyelinating lesions in this area could dysregulate serotonin turnover and consequently, have a role in migraine pathogenesis. ${ }^{11,14}$ Moreover, few reports illustrated that the demyelinating plaques in the brainstem, corpus callosum, and periventricular area might result in migraine headaches as the initial presentation of MS. ${ }^{14,21}$ We identified only seven published case reports, all of which had presenting symptoms of migraine headache. As demonstrated in Table 1, only one adult patient had status migrainosus that had midbrain demyelinating plaque. ${ }^{14}$

We found neither signs of meningeal inflammation nor PAG or brainstem new T2-weighted lesions in our case. As previously reported, migraine could be associated with periventricular MS plaques; however, the role of these lesions on the pathophysiology of migraine is still unclear. $^{24,25}$ In the present case, the causal relationship between migraine and MS was suggested by the subsequent initial reduction of headache following IV methylprednisolone and complete improvement with administration of glatiramer acetate during three months follow-up.

\section{Conclusion}

Migraine headaches are prevalent among patients with MS. Although the presence of headache as the only manifestation of MS attack is rare, new-onset headaches, a change in the pattern of previous episodes, and an inadequate response to standard therapeutic regimens should all be taken seriously and warrant further investigation.

\section{Conflict of Interest Disclosures}

The authors declare that they have no conflict of interests.

\section{Ethical Statement}

The local Ethics committee of Loghman Hakim Hospital has waived the ethics approval for this case report. This study is in accordance with the principles of the Helsinki Declaration and the Medical Research Involving Human Subjects Act (WMO). Also, written informed consent was obtained from the patient. IR.SBMU.MSP.REC.1400.175

\section{References}

1. Dobson R, Giovannoni G. Multiple sclerosis-a review. Eur J Neurol. 2019;26(1):27-40. doi: 10.1111/ene.13819.

Table 1. Studies Reported Migraine Headaches as the Only Manifestation of MS Attack

\begin{tabular}{|c|c|c|c|c|c|c|c|c|}
\hline Study & Year & Gender & Age & Type of Presentation & $\begin{array}{l}\text { Previous History } \\
\text { of Migraine }\end{array}$ & $\begin{array}{l}\text { Signs of Meningeal } \\
\text { Inflammation }\end{array}$ & Location of Lesions & $\begin{array}{c}\text { Response to } \\
\text { DMTs }\end{array}$ \\
\hline \multirow{4}{*}{$\begin{array}{l}\text { Yetimalar } \\
\text { et } \mathrm{al}^{13}\end{array}$} & \multirow{4}{*}{2008} & Female & 27 & $\begin{array}{l}\text { Migraine like } \\
\text { headache }\end{array}$ & No & Not mentioned & $\begin{array}{l}\text { Corpus callosum, } \\
\text { PVL, pons, } \\
\text { midbrain }\end{array}$ & $\begin{array}{l}\text { Not } \\
\text { mentioned }\end{array}$ \\
\hline & & Female & 29 & $\begin{array}{l}\text { Migraine like } \\
\text { headache }\end{array}$ & No & Not mentioned & $\begin{array}{l}\text { Corpus callosum, } \\
\text { PVL, pons, } \\
\text { midbrain }\end{array}$ & $\begin{array}{c}\text { Not } \\
\text { mentioned }\end{array}$ \\
\hline & & Male & 30 & $\begin{array}{l}\text { Migraine like } \\
\text { headache }\end{array}$ & No & Not mentioned & $\begin{array}{l}\text { Corpus callosum, } \\
\text { PVL, pons }\end{array}$ & $\begin{array}{c}\text { Not } \\
\text { mentioned }\end{array}$ \\
\hline & & Male & 31 & $\begin{array}{l}\text { Migraine like } \\
\text { headache }\end{array}$ & No & Not mentioned & $\begin{array}{l}\text { Corpus callosum, } \\
\text { PVL, pons }\end{array}$ & $\begin{array}{c}\text { Not } \\
\text { mentioned }\end{array}$ \\
\hline $\begin{array}{l}\text { Mariotti } \\
\text { et al }{ }^{11}\end{array}$ & 2010 & Female & 5 & $\begin{array}{c}\text { Migraine like } \\
\text { headache, } \\
\text { Status migrainosus }\end{array}$ & No & Yes & $\begin{array}{l}\text { Corpus callosum } \\
\text { PAG, midbrain }\end{array}$ & Yes \\
\hline Lin et al12 & 2013 & Female & 33 & Migraine & Yes & No & $\begin{array}{l}\text { Corpus callosum } \\
\text { PAG, PVL }\end{array}$ & Yes \\
\hline 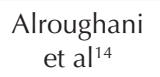 & 2015 & Female & 25 & Status migrainosus & Yes & No & $\begin{array}{l}\text { Corpus callosum, } \\
\text { PVL, midbrain }\end{array}$ & Yes \\
\hline
\end{tabular}

Abbreviations: MS, Multiple sclerosis; CNS, Central nervous system; MRI, Magnetic resonance imaging; CIS, Clinically isolated syndrome; IV, Intravenous; CSF, Cerebrospinal fluid; FLAIR, Fluid-attenuated inversion recovery; DMT, Disease modifying therapy; INF- $\beta$, Interferonbeta; PAG, Periaqueductal gray matter; PVL, periventricular area. 
2. Wang L, Zhang J, Deng ZR, Zu MD, Wang Y. The epidemiology of primary headaches in patients with multiple sclerosis. Brain Behav. 2021;11(1):e01830. doi: 10.1002/brb3.1830.

3. Moreno-Torres I, Sabín-Muñoz J, García-Merino A. Multiple sclerosis: epidemiology, genetics, symptoms, and unmet needs. In: Martinez A, ed. Emerging Drugs and Targets for Multiple Sclerosis. Cambridge: Royal Society of Chemistry; 2019. p. 1-32.

4. Samkoff LM, Goodman AD. Symptomatic management in multiple sclerosis. Neurol Clin. 2011;29(2):449-63. doi: 10.1016/j.ncl.2011.01.008.

5. Graziano E, Hagemeier J, Weinstock-Guttman B, Ramasamy DP, Zivadinov R. Increased contrast enhancing lesion activity in relapsing-remitting multiple sclerosis migraine patients. Neuroimage Clin. 2015;9:110-6. doi: 10.1016/j.nicl.2015.07.013.

6. Headache Classification Committee of the International Headache Society (IHS) The International Classification of Headache Disorders, 3rd edition. Cephalalgia. 2018;38(1):1-211. doi: 10.1177/0333102417738202.

7. Husain F, Pardo G, Rabadi M. Headache and its management in patients with multiple sclerosis. Curr Treat Options Neurol. 2018;20(4):10. doi: 10.1007/s11940-0180495-4.

8. Gebhardt M, Kropp P, Hoffmann F, Zettl UK. Headache at the time of first symptom manifestation of multiple sclerosis: a prospective, longitudinal study. Eur Neurol. 2018;80(3-4):115-20. doi: 10.1159/000494092.

9. Putzki N, Katsarava Z. Headache in multiple sclerosis. Curr Pain Headache Rep. 2010;14(4):316-20. doi: 10.1007/ s11916-010-0126-6.

10. La Mantia L, Prone V. Headache in multiple sclerosis and autoimmune disorders. Neurol Sci. 2015;36 Suppl 1:75-8. doi: 10.1007/s10072-015-2146-9.

11. Mariotti P, Nociti V, Cianfoni A, Stefanini C, De Rose P, Martinelli D, et al. Migraine-like headache and status migrainosus as attacks of multiple sclerosis in a child. Pediatrics. 2010;126(2):e459-64. doi: 10.1542/peds.20092098.

12. Lin GY, Wang CW, Chiang TT, Peng GS, Yang FC. Multiple sclerosis presenting initially with a worsening of migraine symptoms. J Headache Pain. 2013;14(1):70. doi: 10.1186/1129-2377-14-70.

13. Yetimalar Y, Seçil Y, Inceoglu AK, Eren S, Başoğlu M. Unusual primary manifestations of multiple sclerosis. N Z Med J. 2008;121(1277):47-59.
14. Alroughani R, Ahmed SF, Khan R, Al-Hashel J. Status migrainosus as an initial presentation of multiple sclerosis. Springerplus. 2015;4:28. doi: 10.1186/s40064-015-0818-9.

15. Levy D. Migraine pain, meningeal inflammation, and mast cells. Curr Pain Headache Rep. 2009;13(3):237-40. doi: 10.1007/s11916-009-0040-y.

16. Kister I, Caminero AB, Herbert J, Lipton RB. Tension-type headache and migraine in multiple sclerosis. Curr Pain Headache Rep. 2010;14(6):441-8. doi: 10.1007/s11916-0100143-5.

17. Magliozzi R, Howell OW, Reeves C, Roncaroli F, Nicholas $\mathrm{R}$, Serafini B, et al. A Gradient of neuronal loss and meningeal inflammation in multiple sclerosis. Ann Neurol. 2010;68(4):477-93. doi: 10.1002/ana.22230.

18. Magliozzi R, Howell O, Vora A, Serafini B, Nicholas R, Puopolo M, et al. Meningeal B-cell follicles in secondary progressive multiple sclerosis associate with early onset of disease and severe cortical pathology. Brain. 2007;130(Pt 4):1089-104. doi: 10.1093/brain/awm038.

19. Möhrke J, Kropp P, Zettl UK. Headaches in multiple sclerosis patients might imply an inflammatorial process. PLoS One. 2013;8(8):e69570. doi: 10.1371/journal. pone.0069570.

20. Klein M, Woehrl B, Zeller G, Straube A. Stabbing headache as a sign of relapses in multiple sclerosis. Headache. 2013;53(7):1159-61. doi: 10.1111/head.12138.

21. Pakpoor J, Handel AE, Giovannoni G, Dobson R, Ramagopalan SV. Meta-analysis of the relationship between multiple sclerosis and migraine. PLoS One. 2012;7(9):e45295. doi: 10.1371/journal.pone.0045295.

22. Tortorella P, Rocca MA, Colombo B, Annovazzi P, Comi G, Filippi M. Assessment of MRI abnormalities of the brainstem from patients with migraine and multiple sclerosis. J Neurol Sci. 2006;244(1-2):137-41. doi: 10.1016/j. jns.2006.01.015.

23. Johns P. Sensory and motor pathways. In: Johns P, ed. Clinical Neuroscience. Churchill Livingstone; 2014. p. 4959. doi: 10.1016/b978-0-443-10321-6.00004-7.

24. Lapucci C, Saitta L, Bommarito G, Sormani MP, Pardini $\mathrm{M}$, Bonzano L, et al. How much do periventricular lesions assist in distinguishing migraine with aura from CIS? Neurology. 2019;92(15):e1739-e44. doi: 10.1212/ wnl.0000000000007266.

25. Paemeleire K. Brain lesions and cerebral functional impairment in migraine patients. J Neurol Sci. 2009;283(12):134-6. doi: 10.1016/j.jns.2009.02.333. 